\title{
Versiones y revisiones cinematográficas de un mito clásico: las Medeas de Pasolini, Dassin, von Trier y Ripstein (1969-2000)*
}

\author{
Remakes and reviews of cinematography classical myth: \\ Pasolini, Dassin, von Trier and Ripstein s Medeas (1969-2000) \\ María del Carmen Del Barrio Mendoza**
}

\begin{abstract}
RESUMEN
El presente trabajo plantea un profundo análisis de cuatro de las adaptaciones cinematográficas del mito de Medea que se ha considerado tienen una mayor trascendencia, ya sea por su manera innovadora de reinterpretar el mito, por los nuevos elementos estéticos con que se lleva a cabo, por los paralelos que se establecen entre mundo antiguo y mundo moderno o, en fin, por el modo de desplegar el genio artístico que caracteriza a cada uno de los directores escogidos. Cuatro personalidades del mundo del cine que toman el tema de la tragedia de Eurípides o de Séneca, no como mero pretexto para elaborar un mundo nuevo plagado de sus inquietudes, pero tampoco como una traslación literal del tema tal y como lo expresaron sus creadores en el mundo antiguo.
\end{abstract}

\begin{abstract}
This paper presents a thorough analysis of four film adaptations of the myth of Medea, which have been considered as being of great significance. This could be either for its innovative way of reinterpreting the myth due to the new aesthetic elements that are conducted, for the parallels that exist between the ancient and modern world, or due to the way of displaying the artistic genius that each of the chosen directors represent. Four personalities from the film community have taken the theme of the tragedy by Euripides and Seneca, but not as mere pretext to develop a new world plagued with apprehension, nor as a literal transfer of the topic as expressed by their creators in the ancient world.
\end{abstract}

* Este texto surgió en el contexto de un trabajo para la asignatura de «Fuentes para la Investigación» del Máster Universitario en Métodos y Técnicas Avanzadas en Investigación Histórica, Artística y Geográfica y ha sido supervisado y revisado por el Doctor Francisco Javier Andreu Pintado que imparte una sección de la asignatura del mismo Máster en la UNED.

** Universidad Nacional de Educación a Distancia - UNED. 


\section{PALABRAS CLAVE:}

Cine, mitología, tragedia, Eurípides, Séneca, Pasolini, Dassin, Trier, Ripstein, Peplum, meta tragedia, recepción clásica.
KEYWORDS:

Cinema, mythology, tragedy, Euripides, Seneca, Pasolini, Dassin, Trier, Ripstein, Peplum, meta-tragedy, classical reception.

\section{INTRODUCCIÓN}

Han sido muchas las adaptaciones literales y reinterpretaciones que sobre este y otros muchos temas mitológicos se han realizado desde que fueran creados por los grandes literatos y pensadores de la Antigüedad, tanto a nivel cinematográfico como literario, dramático y operístico. Indagar en todas y cada una de las producciones que han tenido como base el tema de Medea en todos los campos artísticos sería una empresa muy ambiciosa para los propósitos de este texto, por ello se propone acotar el tema al campo audiovisual. Se ha considerado oportuna la elección de estos cuatro cineastas porque, además de su originalidad al tratar la tragedia de Eurípides ${ }^{1}$ o Séneca ${ }^{2}$, cada una se produce en cuatro entornos geográficos bien definidos, lo que permite examinar las lecturas que hacen de la tragedia desde mentalidades bien diversas: Ia Italia del Cinema Nuovo donde destaca la imponente personalidad del revolucionario Pier Paolo Pasolini en los años sesenta y setenta; la vida de diáspora que marcó al director americano Jules Dassin causada por el maccarthysmo en Hollywood, además de la Dictadura de los Coroneles durante el período dictatorial que se instauró en Grecia en 1967, país del que procedía su esposa, Melina Merkoúri, y que les hizo llevar una vida dedicada al activismo político y llena de continuos vaivenes; dentro del llamado Cine de la Posmodernidad cabría encajar al singular director de cine danés Lars von Trier, ya que plantea unos métodos y estética cinematográfica que se despliega de los modelos tradicionales de la Historia del Cine; y, por último, el cineasta mexicano Arturo Ripstein que, si bien podría mencionársele dentro de la renovación de los cines latinoamericanos, habría que subrayar su carácter europeo ya que trabajó con Buñuel como asistente de director y ha pasado gran parte de su vida en este continente.

\section{SOBRE LA ANTIGÜEDAD EN EL CINE: PEPLUM/SWORD-AND- SANDAL Y LAS TRAGEDIAS GRIEGAS FILMADAS}

Hablar de los orígenes de la Antigüedad en las producciones cinematográficas haría remontarnos a los primerísimos ensayos de este arte a finales del siglo

${ }^{1}$ EUR. Med. En el caso de tres de ellos, Pasolini, Lars von Trier y Jules Dassin, será el trágico griego el punto de partida para realizar sus films.

2 SEN. Med. Como así se declara tanto en el guión cinematográfico como en el propio film por parte del director, Arturo Ripstein y de la guionista, Paz Alicia Garciadiego en la película Así es la Vida (2000). 
Versiones y revisiones cinematográficas de un mito clásico: las Medeas de Pasolini...

$\mathrm{XIX}$, momento en que se encuentra casi inherente a su deudo el teatro, inmerso éste en los llamados toga plays, de gran fama popular, ambientados en Roma y que, pocos años más tarde vendrían a tener su correlato en la pantalla con el mismo éxito de público. Se crea pues un género dedicado en cuerpo y alma a plasmar tanto los hechos históricos acaecidos en Grecia y Roma, como todo aquel elenco de mitos y pasajes literarios creados en una época tan prolífica en estas artes. Se trata de aquel que han dado en llamar Peplum ${ }^{3}$, haciendo referencia a la prenda con la que griegos y romanos se ataviaban y que inspiró a la crítica francesa a otorgar este nombre al género.

Siguiendo al experto peplumita Rafael de España ${ }^{4}$ se observa que fue en Italia donde primero se realizaron estos nuevos ensayos temáticos en el cine, poniendo como referentes la temprana Gli ultimi Giorni di Pompei (1908) y las afamadas Quo Vadis (1913) y Cabiria (1914). Sería ya tras la I Guerra Mundial cuando las majors estadounidenses toman el relevo a la devastada Italia para realizar producciones con unos presupuestos mucho mayores y con unos resultados más satisfactorios para el impresionable público de aquella época, que observaba atónito las recreaciones de épocas esplendorosas y míticas. Cabría destacar como máximo representante de esta corriente en Estados Unidos al inagotable creador Cecil B. DeMille y, por citar dos de sus grandes aciertos, Samson and Delilah (1949) y The Ten Commandments (1956), dos de las más ambiciosas superproducciones americanas que abundaban por estos años y que relegaron las propuestas italianas a un segundo plano, mucho más modesto en florituras pero que desde los $30 \mathrm{~s}$ asomaba de nuevo gracias al empeño de Mussolini por lanzar una cinematografía nacionalista y poderosa. Como ejemplos centrales del género hay que destacar la italiana Fabiola (1948) de Alessandro Blasetty y la americana Quo Vadis (1951) de Mervyn LeRoy que, aunque con mayor presupuesto y empeños estéticos, no dejan de ser propuestas que tan solo pretenden recrear un pasado mítico y hacer taquilla repitiendo siempre los mismos esquemas y que llegarán a su máximo esplendor con Le Fatiche di Hercole (Hércules, 1957) de Pietro Francisci, protagonizada por Steve Reeves y que pareció ser el pistoletazo de salida para el género propiamente conocido como Peplum. Todo lo que se cree de aquí en adelante serán vagas propuestas masivas e impersonales que hacia mediados de los años sesenta veían ya una temprana pero lógica consumación. Otro exitoso género lanzado por Sergio Leone en Per un Pugno di Dollari (1964) tomará el relevo, haciendo del spaguetti western el nuevo producto de consumo masivo con unas soluciones estéticas similares pero con temáticas actualizadas y sin referentes históricos de la Antigüedad.

Al buscar referentes de la Grecia Antigua es cuando topamos con la sorprendente reducción de producciones ambientadas en esta época. Son varias las ra-

3 Para un mayor acercamiento hacia este tema se recomienda la consulta de: SOLOMON, Jon, $P e-$ plum: el mundo Antiguo en el cine. Madrid, Alianza, 2002; ESPAÑA, Rafael de, El Peplum: la Antigüedad en el cine. Barcelona, Glenat, 1998; PRIETO ARCINIEGA, Alberto, La Antigüedad Filamada. Madrid, Ediciones Clásicas, 2004; MACKINNON, Kenneth, Greek Tragedy into Film. London, Croom Helm, 1986.

${ }^{4}$ ESPAÑA, R., op. cit. y ESPAÑA, Rafael de, «La Antigüedad en el Cine ¿Una Historia de Cartón Piedra? », Clío: Revista de Historia, 97 (2009), pp. 14-16. 
zones que se argumentan para este hecho ${ }^{5}$, pero para centrarnos en las adaptaciones del género literario griego por excelencia en el siglo $\mathrm{V}$ a.C., la tragedia, habría que citar a sus grandes representantes: Esquilo, Sófocles y Eurípides. Mientras las producciones descienden en número respecto al maniqueo Peplum por la dificultad de trasladar unas estructuras tan estrictas como las que caracterizan a la tragedia, se observa una muy acusada mejora en cuanto a la calidad. Como ejemplos significativos cabría citar las adaptaciones de Sófocles, concretamente será en el año 1967 cuando aparezcan dos de las producciones más notables tomando como base el texto sofócleo, como son Oedipus the King de Philip Saville y Edipo Re de Pasolini, la cual emerge con una originalidad que puede dejar perplejo a todo tipo de público, instruido o no en materia trágica. Lejos de adaptar literalmente la obra, toma la base del tema mítico partiendo de la época contemporánea para dar un giro temporal que, si bien podríamos esperar fuese una recreación de la Grecia clásica, se torna en un ambiente y una época completamente incierta, creando en el espectador tal sensación de enrarecimiento que obliga a prestar todos los sentidos al transcurrir de la obra. Muy interesante para comprender lo que más adelante se planteará en la interpretación de su Medea, ya que todo lo ensayado en esta propuesta será llevado en Medea hasta su máxima expresión. En cuanto a las adaptaciones de Eurípides que, por cierto, superan cuantiosamente las de su contemporáneo Sófocles, habría que mencionar la Electra (1962) y Las Troyanas (1971) de Michael Cacoyannis y, del mismo director es la también exitosa Ifigenia (1977).

Las recreaciones de la tragedia griega se refieren a temas intemporales y, de este modo, las adaptaciones que se realizan no son fieles al cien por cien, sino que sirven como inspiración para trasladarlo a un entorno más moderno o, como ocurría en Pasolini, a uno sin retorno, ya que es intemporal e inexistente. Se trata de aquello que los críticos modernos han dado en llamar meta tragedia, y que Kenneth MacKinnon expresó así: «[...] these films constitute attempts at modern tragedies while being simultaneously meditations on the significance of the ancient tragedies to which the films claim a relation [...] they are not free-wheeling modern adaptations with a traceable relation to heroic myth [...] is about Greek tragedy in a broad sense»6. Dentro de esta nueva visión de la tragedia en el cine podríamos incluir filmes como Edipo Re, que ya fue brevemente reseñada, Medea (1969) también de Pasolini y A Dream of Passion (1978) de Jules Dassin, las cuales serán objeto de un estudio más profundo.

\section{LA MEDEA CLÁSICA: EURÍPIDES Y SÉNECA}

La elección de estos dos autores se debe a que, además de haber producido la versión más canónica y estándar del mito, es a ellos a quiénes más remiten los autores posteriores al realizar sus reinterpretaciones del mito, aunque habría que

${ }^{5}$ Ampliamente desarrollado en la hipótesis de PRIETO ARCINIEGA, A., op. cit., pp. 71-79.

6 MACKINNON, K., op. cit., p. 126. 
Versiones y revisiones cinematográficas de un mito clásico: las Medeas de Pasolini...

apuntar una inclinación mayoritaria a escoger la versión del trágico griego antes que la del latino. Puede que se deba a que Eurípides fue el primero en llevar este mito al escenario en una representación teatral, como así consta ocurrió en el año 431 a. C., bajo el arcontado de Pitodoro, durante el primer año de la Olimpiada 87. Así mismo, se representaron también obras de Euforión y Sófocles ${ }^{7}$, los cuales presentaron obras que fueron mejor acogidas por el público ateniense que, quizás, no supo entender una obra de emociones tan humanas como la Medea de Eurípides.

Séneca desarrolló su carrera profesional entre la política, la filosofía, la oratoria y la literatura, dentro de esta última se le atribuyen nueve tragedias, entre las que se cuenta su versión de Medea, considerada como la mejor de las nueve que realizó. Tuvo la obra de Eurípides muy presente, pero pueden observarse diferencias notables en «la concepción dramática, en la economía de la acción, en el trazado de los caracteres, en la actitud y en los movimientos del coro», y estuvo influido también por otros modelos como: Apolonio de Rodas, la Medea de Ovidio (perdida) y la Heroida XII del mismo autor. Sobre todo destaca la originalidad que muestra en la presentación de las muertes de los hijos de Medea, que aparecen asesinados coram populo ${ }^{8}$.

\section{MEDEA Y EL CINE}

\subsection{El infortunio de dos mundos antagónicos: la Medea (1969) de Pasolini}

Pier Paolo Pasolini (1922-1975) comienza sus andanzas en el cine colaborando en guiones a una edad muy temprana, pero no será hasta la década de los cincuenta que despegue su imparable producción cinematográfica. Teniendo en cuenta que Medea fue realizada en el año 1969, sorprende la cantidad de producciones que la preceden. Para comprender mejor sus intenciones, debe recordarse su inseparable labor en el campo literario y en el cinematográfico, y cómo utiliza éste como nexo de unión que engloba todas las artes: «[...] intenta sintetizar todas las formas tradicionales de representación [...] a través de la técnica audiovisual»9.

La película de Medea no pretendió ser una recreación historicista de la tragedia griega, pero tampoco debiera llevar a equívocos la presencia María Callas (1923-1977), ya que tampoco pretendió ser un homenaje a Cherubini. Es una obra realizada desde las más profundas inquietudes intelectuales de Pasolini; de hecho, la producción de la película se acompaña de toda una serie de poemas re-

7 EURÍPIDES, Tragedias. I, El Cíclope; Alcestis; Medea; Los Heráclidas; Hipólito; Andrómaca; Hécuba/ Eurípides; introducción, traducción y notas de Alberto Medina González y Juan Antonio López Férez, Madrid, Gredos, 1991, p. 203.

8 Ante los espectadores. SENECA, Lucio Anneo, Tragedias. Vol. 1, Hércules loco. Las Troyanas. Las Fenicias. Medea. Introducciones, traducción y notas de Jesús Luque Moreno, Madrid, Gredos, 1997, p. 21.

9 GONZÁLEZ, F., op. cit., p. 64. 
alizados en paralelo. A diferencia de la versión griega y latina, aquí se dedica más de la mitad de la cinta para narrar los antecedentes vitales de los dos protagonistas y los entornos donde fueron criados, de vital importancia para entender los mundos que se pone en comunicación y contraste. De este modo, el filme comienza con un extenso monólogo del centauro Quirón (Laurent Terzieff, 19352010) relatando los antecedentes mitológicos del joven Jasón (Giuseppe Gentile, 1943), que en la primera escena es casi un bebé y en la última ha alcanzado la edad adulta. Durante el recitado de Quirón ha habido una transformación, tanto en el argumento de este, que comienza elogiando todo aquello que es mítico y religioso en su forma de centauro y durante la infancia de Jasón pero, acto seguido, el héroe crece, el centauro es ahora humano y lo que relata corresponde a un ideal racionalista y desacralizado. Tras esta inicial confrontación de dos mundos en un mismo personaje, Pasolini nos traslada a la tierra de Medea, la Cólquide sagrada, donde están a punto de realizar un sacrificio en clave ritual que tiene por ofrenda un joven aldeano. Más tarde es decapitado y descuartizado para así poder repartir sus pedazos y su sangre sobre los yermos campos del territorio, en medio de una solemne celebración ritual.

La expedición de los argonautas ya había arrancado; desembarcan en la Cólquide saqueando y asaltando viviendas. Al mismo tiempo la sacerdotisa pide ser preparada para rezar en el templo y, más adelante, en plena noche, tiene un repentino despertar que la lleva de nuevo al templo donde, de repente, se encuentra ante el vellocino de oro y ante la presencia de un joven con el que cruza una intensa mirada que la hace desfallecer. Cuando despierta, una fuerza interna desconocida la lleva a robar el vellocino con ayuda de Apsirto. Acto seguido se lo entregan a Jasón y, tras asesinar a su propio hermano, huye con ellos esparciendo los pedazos de este último para que su padre no pudiera darles caza. Cuando realizan la primera parada en la costa ya se siente perdida. Sin embargo, prosigue el viaje junto a ellos, que todavía ha de pasar por Yolcos, lugar en el que le es entregado a Pelias el vellocino de oro, ya desposeído de su valor. Jasón y Medea se separan de los argonautas y prosiguen su camino hasta Corinto donde, tras una trascendental conversación entre Jasón y el Quirón-hombre, se llega al momento donde verdaderamente arrancaban las tragedias de Eurípides y Séneca. Después de diez años de felices vivencias en la ciudad de Corinto, Medea sale de su vivienda y descubre que Jasón contraerá matrimonio con Creúsa. Todo lo que sigue en la película está ya, con ciertas licencias, en concordancia con el relato clásico: Creón exilia a Medea, ésta envía a los dos niños con las envenenadas ofrendas para matar a la princesa y, por último, asesina a sus propios hijos.

Se podría decir que «su meta no es tanto filmar una historia de amor y celos, marcado por el hecho de que una madre llega a tal nivel de desequilibrio que se convierte en parricida, sino que subraya más bien el contexto en el que la acción se desenvuelve. Transforma la historia no en una confrontación entre personajes, sino entre mundos» 10 .

10 SALVADOR VENTURA, Francisco, «La Recreación Estética de una Grecia Mágica. La Cólquide en la Medea de Pasolini», Boletín de Arte, 25 (2004), p. 701 
Versiones y revisiones cinematográficas de un mito clásico: las Medeas de Pasolini...

\subsection{Las Medeas de Dassin: A Dream of Passion (1978)}

La Medea que presenta Jules Dassin (1911-2008), con el título A Dream Of Passion (1979) es, de nuevo, una traslación del drama de Eurípides a los intereses del director, que nos lleva a la Grecia contemporánea donde se está preparando la misma obra del trágico griego para ser interpretada en teatro por una actriz afamada; en palabras de MacKinnon: «[the film] atempt to explore the relevance of contemporary actuality to a modern production of Euripides Medea and also, to an extent, the relevance of the ancient play to an understanding of contemporary actuality ${ }^{11}$. La historia narra un momento vital de la actriz Maya (Melina Merkoúri) (1920-1994) que regresa a Atenas para realizar el papel protagonista de una nueva versión de la Medea de Eurípides, durante la cual se harán evidentes las tensiones amorosas y profesionales que brotan entre el director, Kostas (Andréas Voutsinas, 1932-2010) y la actriz. Para poder penetrar más profundamente en su personaje, Maya acuerda una visita en la cárcel con la infanticida Brenda Collins (Ellen Burstyn, 1939), la cual era conocida con el sobrenombre de «La Medea de Glyfada» por el asesinato de sus tres hijos al enterarse de la infidelidad de su marido y tras varias amenazas de abandono. Poco a poco, la actriz va comprendiendo las razones que llevaron a la asesina a tan fatales actos, de modo que llega un momento en que el personaje mítico, la actriz y la asesina contemporánea se funden de tal modo que resultan casi indisolubles.

\subsection{Desequilibrio y venganza en la Medea (1987) de Trier}

Lars von Trier (1956-) presenta, a raíz de un guión inacabado de Carl Th. Dreyer (1889-1968), la producción televisiva de Medea, que tampoco es un reflejo fiel de Eurípides, así como Dreyer expresaba: «This screenplay is not directly based on the tragedy of Euripides, but it is inspired by his play. At the same time, the film is an attempt to tell the true story that may have inspired the great greek poet» ${ }^{12}$.

La trama se sitúa en un incierto medievo en las tierras de Dinamarca, que abre con una imagen de la protagonista, Kirsten Olesen (1949) tendida en la orilla del mar, queriendo ser tragada por la marea, como si ya hubiera tenido lugar toda la tragedia. Tras coger un profundo aliento, algo la hace despertar de su trance y a lo lejos divisa una embarcación capitaneada por el rey de Atenas, Egeo, el cual garantiza procurarle asilo en su ciudad, como si ya tuviese planeada toda su venganza. Nos conduce luego al entorno palaciego de Creonte donde advertimos un Jasón, Udo Kier (1944) oportunista que quiere ascender en su carrera política mediante el matrimonio con Creúsa. Durante los encuentros entre Medea y Creonte, cuando le comunica su exilio, y los que tienen lugar entre ésta y Jasón, se hace palpable la relación amorosa que Medea entabla con sus hijos. Estos últimos, de

11 MACKINNON, K, op. cit., p. 156.

12 DREYER, Carl Theodor y THOMSEN, Preben, Guión Cinematográfico de Medea. http://english.carlthdreyer.dk/Service/Dreyer_News/2011/Dreyers-Medea-script-online.aspx. 
nuevo, son los encargados de llevar a Glauce los mortíferos regalos que la conducirán a una agonizante muerte, representada en la imagen paralela de un caballo que relincha y se retuerce hasta que su cuerpo sin vida cae desplomado en la orilla del mar. Lo que sigue va aumentando la tensión en el espectador, que ya sabe el destino de los pequeños que, portados en un carro de madera por su madre, son conducidos hasta una colina que preside un árbol en el que serán colgados por ella misma. Cuando Jasón llega a la escena del crimen ya es demasiado tarde y su rostro de rabia y dolor se superpone a la imagen triunfal de Medea, que ya ha embarcado en la nave de Egeo para partir impune hacia Atenas.

\subsection{Ripstein: la actualización del drama senequiano en el Mexico contemporáneo. Así es la Vida (2000)}

Arturo Ripstein (1943) se ha dedicado casi en exclusiva a la adaptación de obras literarias y películas antiguas. No se podría tener una visión completa de su cine sin introducir a su mujer y guionista, Paz Alicia Garciadiego (1949-), encargada de adaptar todos los textos que llevan a la pantalla, los cuales son exprimidos hasta tal punto que su correlato en cine resulta otro producto bien diferenciado: «[...] Una vez que tengo una novela en mis manos lo que hago es ser rigurosa y absolutamente desleal con el autor» ${ }^{13}$.

Así es la Vida (2000) nos presenta a una Medea mexicana, Julia (Arcelia Ramírez, 1967), atrapada en el interior de una angustia existencial al haber sido abandonada por el oportunista Jasón, representado por un boxeador fracasado llamado Nicolás (Luis Felipe Tovar, 1961). La película abre filmando el lamento de Medea, en el interior de su humilde dispensario donde se dedica a la «medicina informal». Más adelante aparece en escena la que toma el papel de nodriza, su madrina Adela (Patricia Reyes Spíndola, 1953), que la consuela y reprende por haber confiado en un hombre. Se intercalan los lamentos de Julia con el resto de personajes: La Marrana (Ernesto Yáñez, 1960), un rey Creonte de un humilde barrio mexicano, temido y respetado, y que custodia a su hija Raquel (Creúsa) como un diamante en bruto. Esta última ha decidido contraer matrimonio con Nicolás, por lo que La Marrana, casero de Julia, le ordena marchar del apartamento para que no se entrometa en los felices planes de su hija. En este caso la muerte de Raquel y La Marrana sólo forma parte de la imaginación de Julia, mientras los niños sí son asesinados. Seguidores declarados de la versión latina del mito de Medea, no se basan fielmente en este, pero plasman los estragos causados por el abandono en la psique de la protagonista, en un mundo contemporáneo que plantea un escenario distinto, pero con las mismas pulsiones internas.

13 BUSTAMANTE, María, «Ripstein y su Carnaval de Sodoma: entrevista con Arturo Ripstein», Revista de la Universidad de Mexico, 30 (2006), p. 83. 
Versiones y revisiones cinematográficas de un mito clásico: las Medeas de Pasolini...

\subsection{Análisis y comparación de las propuestas cinematográficas}

\subsubsection{Ambientación y mundos imaginados}

En la primera de nuestras Medeas habría que mencionar cuatro escenarios bien diferenciados que trasladaron a Pasolini a tres entornos geográficos distintos, desde la laguna di Grado en el alto Adriático donde se encuentra la cabañita del centauro Quirón y la Piazza dei Miracoli de Pisa que representaba Corinto, ambos en Italia, opuesto a un escenario completamente incivilizado y primitivo en las tierras áridas de Siria y Turquía. Estas últimas representaban la Cólquide de la hechicera Medea, un lugar mítico que sólo aparece mencionado al principio de la tragedia de Eurípides: «¡jalá la nave Argo no hubiera volado sobre las sombrías Simplégades hacia la tierra de la Cólquide [...]»14.

En la laguna di Grado se expone el soliloquio del centauro Quirón, que expresa la parte mítica durante la niñez del héroe: «Todo es santo [...]. No hay nada natural en la naturaleza, muchacho mío, tenlo bien presente. Cuando la naturaleza te parezca natural, todo habrá terminado -y comenzará algo distinto- [...] ¡ En cada punto donde se detienen tus ojos está escondido un dios! ${ }^{15}$. Revela cómo toda la naturaleza está plagada de elementos religiosos, siguiendo diversas fuentes de antropología de las religiones, con especial interés en el Tratado de Historia de las Religiones de Mircea Eliade ${ }^{16}$. Pero cuando Jasón alcanza la edad adulta, el centauro es un humano más, representante del golpe de realidad que adquirimos con la edad adulta. Así mismo, lo que ahora manifiesta el hombre-Quirón es lo siguiente: «Lo que el hombre, descubriendo la agricultura, vio en los cereales, lo que aprendió de esta relación, lo que comprendió del ejemplo de las semillas que pierden su forma bajo tierra para luego renacer, todo esto significó la lección definitiva [...] Pero ahora esta lección definitiva no sirve más [...] En efecto no hay ningún Dios [...] Los dioses son mentiras, los cultos, locuras, sólo fueron inventados por la civilización agrícola, etc. Ahora hay que sustituir la metafísica por algo; este algo es el éxito terrenal: el éxito se obtiene a través del escepticismo y la técnica» 17 . Tras estas profundas y contradictorias cavilaciones se nos traslada a la Cólquide sagrada. En este lugar se reconstruye una tierra mítica donde no pueden establecerse analogías historicistas concretas; se presenta con gran nivel de extrañeza ante el espectador que, aunque no acierta a situarlo, siempre puede definirlo como primitivo, exótico, religioso y alejado de parámetros occidentales. Se trata de una mezcolanza que combina paisaje árido y «lunar», casas excavadas en la roca, actores autóctonos de la zona de la Capadocia ${ }^{18}$, trajes extravagantes traídos

14 EURÍPIDES, op. cit., p. 213. EUR, Med, 1-6.

15 FABROSCHI, Azucena A., «Medea, de Pasolini, por Pasolini», Stylos, 7 (1998), p. 167-168.

16 Como así apunta el propio Pasolini en el guión cinematográfico de la película, en la escena 11, cuando Jasón pasa de la niñez a la madurez, dejó anotado: «Cf. Teorías de Eliade, etc». Publicado en: PASOLINI, P. P., II Vangelo Secondo Mateo, Edipo Re, Medea, Roma, Garzanti Editore, 1991.

17 FABROSCHI, A. A., op. cit., p. 168-169. Dentro del guión cinematográfico de Medea. Escena 15.

${ }_{18}$ Concretamente en tres zonas de Turquía: Capadocia, Anatolia y Ea (en la zona de Göreme y Urgüp). Tomado de GONZÁLEZ, F., op. cit., p. 125. 
de múltiples culturas y música extenuante propia de ritos sagrados tibetanos. Un grupo de personas se reúnen en torno a un fin superior, religioso: la purificación de la tierra a través del sacrificio humano. Un joven lugareño es ofrecido para ello, envuelto en un ambiente de festividad atávica, donde cantan y bailan, mezclándose los vivos con individuos enmascarados, que representan a los muertos ${ }^{19}$. La confrontación entre mundos se da cuando aparece Jasón en la Cólquide y Medea cae desmayada ante su presencia, lo que la hace despertar a un mundo diferente donde ya no encontrará los pilares básicos que trascienden de su experiencia vital. Medea huye con ellos, pero irá sufriendo una evolución que más bien se produce en regresión, lo que Pasolini explica como «el mito de San Pablo al revés»: «[...] Una especie de conversión al revés. Imagínese que en el momento en el que cayó del caballo San pablo hubiese sido creyente, y que el traumatismo le hiciese perder la fe. Medea es víctima de la misma fulguración [...]»20. A partir de la huida, experimenta diferentes fases que van desde la fascinación del nuevo mundo con el que se encuentra, representado en la figura de Jasón; más adelante siente pánico, al desembarcar en una isla y ver que no santifican el lugar donde van a acampar, cuando pronuncia lo siguiente: «No repetís el primer acto de Dios... Vosotros no buscáis el centro. ¡No!»21. Este pánico se suple con la entrega carnal a Jasón: «[Medea] en el amor encuentra, de golpe (humanizándose), un sustituto de la religiosidad perdida; en la experiencia sexual reencuentra la perdida relación sagrada con la realidad. Así el mundo [...] se reconstruye de golpe delante de ella»22. El tercer estado lo constituye el desengaño que se le revela en Corinto, causado por el abandono de Jasón. Aquí no se trata tanto, como en Eurípides, de una deshonra causada por la traición a las promesas del matrimonio, sino más bien de una recaída en la desesperación al ver perdido ese cuerpo que le permitía reconstruir su mundo de certidumbre y sacralidad ${ }^{23}$.

Por otro lado Jasón es «un retrato de la racionalidad burguesa, que desprecia o compadece todo aquello que no se le parece» 24 . Lo que ahora necesita es legitimar su poder, por lo que decide casarse con Glauce, sin importar la promesa hecha a Medea años atrás. Esta racionalidad salvaje moderna representada en la actitud de Jasón, se complementa con el escenario en el que se in-

19 El propio Pasolini comenta la simbología de las máscaras, representantes de los muertos, los cuales menciona incluso en una composición poética compuesta durante el rodaje: Preghiera su commisione, publicado en: PASOLINI, P.P., op. cit., p. 565. Tomado de: SALVADOR VENTURA, F., op., cit., p. 705.

20 GONZÁlEZ, F., op. cit., p. 96.

21 Esto también está relacionado con la antropología de las religiones de Eliade: «La revelación del espacio sagrado tiene un valor existencial para el hombre religioso: nada puede comenzar, hacerse, sin una orientación previa, y toda orientación implica la adquisición de un punto fijo (ese centro que buscaba Medea) [...] el «Centro del Mundo» [...] equivale a la Creación del Mundo» (ELIADE, Mircea, Lo Sagrado y lo Profano, Madrid, Guadarrama, 1967, p. 27). Tomado de: FABROSCHI, A.A., op. cit., p. 176.

${ }_{22}$ FABROSCHI, A. A., op. cit., p. 177. También relacionado con Elíade, donde se aclara que no es un simple acto fisiológico sino un «sacramento» o comunión con lo sagrado (ELIADE, M., op. cit., p. 22).

${ }_{23}$ Las fases experimentadas de Medea que expone GONZÁLEZ GARCÍA, Fernando, «Medea y Jasón en Pier Paolo Pasolini», El Conocimiento del Pasado: una herramienta para la igualdad, Madrid, Plaza Universitaria Ediciones, 2005, p. 474.

${ }^{24}$ GONZÁLEZ GARCÍA, F., op. cit., p. 475. 
Versiones y revisiones cinematográficas de un mito clásico: las Medeas de Pasolini...

serta la ciudad de Corinto, filmada en la célebre Piazza dei Miracoli de Milán, provista de una arquitectura severa, racional y proporcionada, que le ayuda a completar la metáfora visual de contraste entre mundo sacro-profano. La ciudad queda inserta en un alto defendido por murallas, que pertenecen a Aleppo, pero la casa de Medea se sitúa fuera de ellas, acentuando más todavía su abandono y su no integración en la nueva sociedad civilizada. Estas oposiciones visuales se complementan con toda una serie de elementos estéticos: contraste entre secuencias habladas y otras donde prima un silencio total casi ritual; otras de un estatismo que se enfrenta pero a la vez dialoga con otras de un movimiento intensísimo, etc. Todo en este filme está al servicio de la recreación de un mundo centrado en oposiciones intensas: «[...] La tesis/ y la antítesis coexisten con la síntesis: He aquí/ la verdadera trinidad del hombre, ni prelógico ni lógico/ sino real. Sé pues sabio con tus síntesis/ que te permitan avanzar (y progresar) en el tiempo/ (que no existe) $[\ldots]{ }^{25}$.

Dassin declaraba en A Dream of Passion, traducida en español como Gritos de Pasión, haber tenido siempre en mente la realización de una Medea, pero lo que le llevó a hacerlo realidad fue la noticia de una infanticida real ${ }^{26}$. Ian Christie afirma su inserción en varios estilos de los que participa: nos habla de esa introducción de play within a play (teatro dentro del teatro), pero además apunta otro menos definido: el artist $s$ apologia, en el cual la vida de la protagonista como actriz acaba asumiendo el personaje que interpreta, fundiéndose en uno, dentro de una metafiction donde el «arte» y la «vida» actúan a la par. En tercer lugar apunta otro género en el que encaja de forma más evidente, como es el backstage story, buscando los orígenes en el mundo del teatro de fin de siécle. Por último, lo relaciona con producciones en las que se hace homenaje a una venerada obra dentro del género, como ocurre con Brenda, cuya intérprete, Ellen Burstyn, había actuado en el papel de madre aterrorizada en The Exorcist (1973) seis años atrás, con la que la gran mayoría del público de aquellos años establecería claras analogías ${ }^{27}$. En cuanto a la ambientación, se encuentra en Dassin una contemporánea mucho más sencilla, tanto estética como conceptualmente hablando, respecto a la que Pasolini planteaba una década atrás.

Lars von Trier muestra un lugar incierto, cubierto de una nebulosa atmósfera, un entorno lóbrego, muy propio de las tierras nórdicas y, con varias técnicas, como son el doblaje de diálogos, el reajuste del color y la luz o las copias en vídeo tras el rodaje hace que se nos presente como un ambiente lejano: «the result of the laborious experimental process was a train of images that seemed on the verge of dissolving in murk and graininess ${ }^{28}$. En este intento de poner en la piel de la audiencia ateniense al público cinematográfico actual, juega también con los efectos

25 DUFLOT, Jean, Conversaciones con Pasolini, Barcelona, Anagrama, 1971, p. 188-189 (poema de Pasolini escrito en Junio de 1969, durante el rodaje de la película).

26 MACKINNON, K, op. cit., p. 157.

27 Reflexiones de lan Christie en HALL, E., op. cit., p. 160.

${ }^{28}$ STEVENSON, Jack, Lars von Trier, London, British Film Institute, 2002. Citado por JOSEPH, S. y JOHNSON, M., op. cit., p. 115. 
sonoros, intentando reproducir aquellos que se oyesen durante la representación teatral de la Medea de Eurípides, dentro de «an open-air theatre overlooking a busy harbor [...] Natural sounds have more importance than the voices of characters 22 . La atmósfera de la escena crucial de la muerte de los niños aparece intensificada por los elementos que la rodean: una luz radiante en contraste con la imperante oscuridad que primaba en el resto de la película, el estridente cantar de los pájaros o un silencio ensordecedor que sólo se ve roto cuando el niño mayor pregunta que qué va a colgar en el árbol, a lo que Medea responde: «Algo que amo»30; un árbol que aparece en un promontorio a modo del calvario cristiano.

Al igual que ocurría en Dassin, Ripstein muestra un entorno contemporáneo para su Medea, pero esta vez aparece todavía más enrarecido porque se encuentra en un entorno extra europeo, un Mexico empobrecido, años luz del lugar donde vio la luz por primera vez el mito. Si el drama del abandono fuera poco, se nos presenta en un ambiente suburbial y ruinoso, uno de esos inframundos que tanto gusta a Ripstein captar en sus filmes, desde el cual observa las relaciones humanas «desde sus lados más escondidos, como pueden ser el sexo o la familia, los cuales son también, los más sórdidos precisamente porque quedan ocultos» 31 .

\subsubsection{Tratamiento de los personajes secundarios}

\section{A) EL CORO}

En Pasolini el coro aparece representado en la Cólquide por una serie de campesinas cantando mientras realizan sus labores en el campo. Al igual que en la tragedia griega se lamentan y auguran desgracias venideras. Así presagian la venida del héroe que destruirá su reino: «Nuestro reino tenía por límite el cielo, pero él vendrá y agujereará el cielo y así nuestro reino terminará. Él reinará mientras nosotros lloraremos, porque tiene en la boca el nombre de la blasfemia y por donde él pase todo será árido [...] Nosotros conocemos los viñedos pero no el mar, [...] y él viene del mar. [...] Mientras estemos orando caeremos por tierra como epilépticos y, cuando nos levantemos de nuevo, no conoceremos más a Dios. Él no sabrá que los muertos vuelven con la cara cubierta por las máscaras como los ratones de sus madrigueras. Pero será hermoso y seguro de sí mismo y gustará a las muchachas como un Dios» 32. Puede observarse cómo este coro ya vaticina las fases que experimentará Medea desde su encuentro con Jasón: fascinación, pánico, desengaño y venganza.

29 JOSEPH, S. y JOHNSON, M., op. cit., p. 116.

30 JOSEPH, S. y JOHNSON, M., op. cit., p. 128. Comparan el sacrificio con la imagen cristiana de matter dolorosa, al arrodillarse ante el árbol la sollozante Medea como ya lo hizo la Virgen María en la base de la cruz y tantas veces representado en al arte occidental. Hacen alusión también a la toma en primer plano de la herida del niño que antes había sido curada por su madre, como paralelismo con los estigmas cristológicos.

31 TOVAR PAZ, Francisco Javier, «Medea de Séneca en Así es la Vida (2000), filme de Arturo Ripstein", Revista de Estudios Latinos: RELat, 2 (20002), p. 179.

32 PASOLINI, P. P., op. cit., p. 547-548. 
Versiones y revisiones cinematográficas de un mito clásico: las Medeas de Pasolini...

El papel del coro aparece en Ripstein y Garciadiego personificado por el grupo de mariachis «Anselmo Fuentes y sus hermanos» que nos hablan de la esencia de mujeres y hombres, a la vez que van narrando las historias de los caracteres de la película. Intentando actuar de la mano de la madrina, el coro aconseja a Julia que olvide a Nicolás, que ya nada tiene solución, evocando una Arcadia mítica que se ha perdido y debe ser relegada al olvido para no sufrir más: «[...] Allá todos los amores tienen un final feliz./ Los hombres forman familia./ A las mujeres respetan. [...] Aquel mundo está lejos. [...] Ahora queda el consejo, que te damos con amor. Olvida la Arcadia aquella, que te crió con amor, que ahora sólo te quedan, angustias del corazón...»33.

El coro en las Medeas de Dassin y Trier tiene un protagonismo mucho menor. En la del director danés aparece uno impersonal que queda representado por las imágenes de la naturaleza y la banda sonora, además de otro personal que hacen las veces del séquito de Creusa y de Jasón ${ }^{34}$, pero no tiene la función prefigurativa que en las películas de Pasolini y Ripstein. El coro que ofrece Dassin está muy presente, en cierto modo porque forman parte de la representación teatral que se está preparando. Abren recitando el texto de Eurípides en griego antiguo y cierran el filme representando las partes cantadas de los últimos versos de la tragedia euripidea, en griego moderno. Acompaña y comenta la evolución psíquica de la Medea en escena y de la Maya actriz, recitando versos tomados directamente de la tragedia de Eurípides.

\section{B) NUEVOS PERSONAJES}

En cuanto al primer caso, Pasolini otorga un protagonismo a la figura del centauro Quirón, inexistente en el drama de Eurípides y Séneca, el cual se presenta en dos formas: la humana racional y la híbrida mitológica. A diferencia de lo que ocurría en el inicio de la obra, durante el diálogo en Corinto, el centauro ya no puede hablar, como si al adquirir Jasón la edad adulta y una conducta racional hubiera dejado sin argumentos al personaje mítico que queda sustituido por las consideraciones del Quirón-humano: «Él no habla mucho, naturalmente. Su lógica es tan diferente a la nuestra que te resultaría incomprensible. Puedo hablar yo por él. [...] Es su influencia, a pesar de tus cálculos y tus interpretaciones, la que te hace amar a Medea». En este desdoblamiento, el personaje sirve también como presagio de las desgracias venideras, advirtiendo a Jasón de la terrible fisura que escinde su mundo y el de Medea, dice: «[...] Medea vive la confusión y la tragedia de una mujer antigua en un mundo en el que lo que para ella eran verdades ya no significan nada. La pobre experimentó una conversión a la inversa y no puedo recuperarse»35.

33 GARCIADIEGO, P. A., op. cit., p. 47

34 JOSEPH, S. y JOHNSON, M., op. cit., p. 117.

${ }^{35}$ Extractos del guión de la película durante el diálogo entre el Centauro y Jasón en la Piazza dei Miraccoli de Milán. 
En la propuesta de Trier y como explica Magdalena Okhuysen ${ }^{36}$, Egeo toma un papel fundamental, ya que su presencia sirve para dar un sentido a la historia y a la composición, imprimiendo al drama un impulso retrospectivo, ya que buscaremos los porqués de los hechos en estas escenas. En la versión clásica aparece cuando Medea y el coro se lamentan de su desgraciado destino, para resolver la situación, aunque Aristóteles opinase que no era un marco verosímil para construir la obra y lo tachó de artificioso recurso. No fue un truco lo que inspiró a Eurípides a elegir la escena de Egeo, ya que incluso sirve para dar una vuelta de tuerca más. El público podría esperar que al ofrecer una salida de refugio en Atenas para Medea, los niños pudieran salvarse, pero todo el resto del drama conduce a la desesperada Akrasia de Medea, decidiendo que deben morir y además en sus manos. En el caso de Trier, Egeo aparece desde el principio del filme, cuando Medea está a punto de desaparecer absorbida por la marea, pero sale del agua, concediendo a la inclusión de la figura de Egeo en la tragedia griega la categoría de poderoso acierto. Por tanto, la introducción de tres escenas de Egeo en la película supone un homenaje a la solución tomada por Eurípides y manifiesta, en este punto, su lealtad al texto clásico, aunque expresándolo en un lenguaje propio de un medio, estética y genio nuevos.

Es también muy notable la importancia de Glauce en la obra de Trier, que viene determinada por la propia psique de Medea. Ella está obsesionada con la princesa y se la presenta como la versión virginal de Medea, de ahí que no consume su amor con el héroe ${ }^{37}$. Es lo que Joseph y Johnson relacionan con la liberación final de Medea que se ha deshecho de la mujer que la deshonraba (Glauce) y de los niños que la reafirmaban como madre y, como consecuencia, la hacían «padecer» esa virginidad perdida; ahora es una mujer libre y suelta su melena al viento.

Se presenta un elemento nuevo en Ripstein con la introducción del medio televisivo como un personaje más, que funciona como «prefigurador» de los acontecimientos de la historia que se narra. Tovar Paz lo interpreta como la «victoria de la imagen» frente a la palabra, del mismo modo que Séneca intentó el triunfo de la representación mediante la tragedia frente a la imposibilidad de la filosofía de explicar ciertos temas a través de la razón. De este modo encontramos personajes como la metafórica «mujer del tiempo», que sólo augura «fuertes aguaceros» que se «cobraron vidas», tempestades como las que recorren lo más íntimo del alma de Julia. Aparecen igualmente imágenes de Julia y Nicolás en pleno acto amoroso mientras Raquel y Nicolás hacen lo mismo, sin saber quién encendió el artilugio. También director y equipo técnico se cuelan en alguna escena, como en

${ }^{36}$ OKHUYSEN, Magdalena, «El texto dramático de Eurípides en la escena cinematográfica. La Medea de Eurípides y Lars von Trier», Université Invitée, 4 (2007),

37 JOSEPH, S. y JOHNSON, M., op. cit., p. 119. Explican interesantes analogías entre la boda de Glauce-Jasón y el Throne Ludovisi donde se representan escenas de casamiento y muerte; entre la María Falconetti de Dreyer y la corona que también acaba con Glauce; además de la escena en que Jasón visita a Medea, que alude a un tapiz flamenco, la chica y el unicornio, en la que aparecen ambos separados por un telar. Se representa la discusión en la que Medea suplica ser perdonada y no exiliada, la cual acaba con un violento movimiento de Jasón rompiendo ese instrumento, como si al hacerlo también se desmembrase la familia que había tejido anteriormente con Medea. 
Versiones y revisiones cinematográficas de un mito clásico: las Medeas de Pasolini...

la que Raquel se preparaba para la boda. La televisión también es protagonista en la «apoteosis» final de la Medea mexicana cuando, Julia, tras asesinar al segundo hijo toma un taxi y desaparece en el interior de un televisor, como si toda la historia narrada acabara siendo parte de esos folletines televisivos tan abundantes en América latina. Como subraya Francisco Javier Tovar: «donde no llega la razón llega la televisión», como cuando no somos capaces de explicar las causas de un trágico suceso decimos «así es la vida», del mismo modo la televisión no da explicaciones racionales y, por tanto, puede dar salida a un suceso inexplicable como es el que una mujer mate a lo que más quiere por despecho ${ }^{38}$.

\subsubsection{Crímenes filmados: filicidio, aborto y ensoñaciones}

Tanto en A Dream of Passion como en Así es la Vida se representan los asesinatos en dos niveles bien diferenciados. Por un lado nos encontramos el tema del aborto que, en la película de Dassin es confesado por la propia protagonista, la cual confiesa haberse provocado un aborto. En el caso de Ripstein, el tema del aborto es fundamental, al cual se refieren en una escena en el dispensario donde Julia ayuda a una joven, Estela, a abortar, y dice: «Esta vida duele mucho, entonces si no lo dejas que nazca, la vida jamás le va a doler. Eso es amor de madre, amor del bueno»39. Pero se refieren sobre todo al daño que causaría en la mujer si lo dejan nacer. Es por ello que la madrina, Adela, conserva su feto muerto, porque de esta manera nunca le abandonará, del mismo modo que la Medea mítica se lanzó en su carro de Helios con los cuerpos sin vida de sus dos hijos que, al morir de una manera tan terrible se hacen inolvidables y, por tanto, inmortales ${ }^{40}$.

Tanto Pasolini como Ripstein muestran en sus películas dos ensoñaciones que tienen como temática las muertes de Glauce y Creonte - Raquel y La Marrana. En el primer caso Medea tiene un sueño que será, de nuevo, regresivo: quiere regresar al pasado mítico de la Cólquide, a su esencia de sacerdotisa y a los rituales divinos. Sólo está presente en el guión y hace que la idea de muerte se torne natural de nuevo en su cabeza, el sacrificio como algo necesario para que surja algo nuevo. Lo que sí se filmó fue la primera muerte imaginada, en la que Creusa se precipita desde lo alto de las murallas del palacio, seguida de Creonte. La muerte verdadera vendrá por las ofrendas envenenadas que los niños portan al palacio. Creusa arde en llamas hasta que finalmente muere junto a su padre, al intentar procurarle auxilio. Reflejo de una ensoñación es también la muerte de Raquel y La Marrana, que se presenta tras contemplar Julia un incendio en la televisión. De repente se nos transporta a un incendio en el vecindario

${ }^{38}$ Varias de las reflexiones apuntadas se han tomado del texto TOVAR PAZ, F. J., op. cit., pp. 190-192.

39 GARCIADIEGO, Paz Alicia, op. cit., p. 70.

40 VERNANT, Jean-Pierre, Mito y Tragedia en la Grecia Antigua, Madrid, Siglo Veintiuno de España, 1982. Mencionado también en el texto de: TOVAR PAZ, F. J., op. cit., p. 189. 
que ha tenido por víctimas a los que ella quiere ver morir, desde una visión subjetiva de la protagonista.

En el caso de Dassin y Trier no se dan estas muertes soñadas, sino que se muestran abiertamente, remarcando la locura de las Medeas, ya que aparece en ambas el asesinato de los niños como muestra del egoísmo adulto. En la película del danés, el hijo mayor se hace consciente de esta situación y ayuda a la madre en la tarea. Las razones que dan para este auto-asesinato encajan con la propia biografía del director, quien tantas veces ha confesado sus traumas de la infancia. Ian Christie habla de la toma de conciencia del pequeño en tan terrible asunto: «[...] the older boy is a saddened, knowing spectator of his mother s disgrace. He realices that he and his brother must die in order to complete her revenge on their faithless father ${ }^{41}$. Los asesinatos de los niños en Trier son captados frente al espectador, haciendo hincapié en lo insoportable de la escena, ya que el ritual slow-motion al que Trier nos tiene acostumbrados para escenas tan patéticas tiene una duración en este caso de diez estremecedores minutos. Puede que sea en este punto donde más pone a prueba al espectador moderno respecto al griego, ya que nos sentimos horrorizados ante un crimen que ha sido anticipado desde los inicios del filme, no obstante, y teniendo en cuenta lo acostumbrado que está el espectador contemporáneo a presenciar crímenes infundados y pueriles en la pantalla, sorprende cómo somos incapaces de soportarlo. Esta angustia puede que sea la misma que sintieron los espectadores de la Atenas del siglo $\mathrm{V}$ a.C. al ver cómo Medea se tomaba la justicia por su mano sin intervención divina. Por otra parte, el egoísmo de Brenda queda expresado en sus enloquecidos diálogos con Maya, cuando le cuenta que, tras asesinar a sus hijos el día del padre como regalo, escribió una carta mezclando pasajes de la Biblia con frases blasfemas mientras se comía un trozo de tarta. Pero lo único que quiere Brenda es que nadie piense que está loca, porque si así fuera, su obra no tendría ningún sentido. Refiriéndose a Roy, el Jasón de la «Medea de Glyfada», dice: "Cuando dormía, le miraba. Cuando les daba de mamar sólo pedía que no estropeasen mis senos para que Roy pudiese disfrutarlos». Intenta probar su cordura pero manifiesta lo contrario, sumida en una profunda pena interior grita y se encoge en posición fetal desde su celda, al igual que la Medea de Trier ahorca a sus hijos no con menos dolor: ellas no han escogido a esos niños, son prescindibles, ambas amaban a sus hijos, pero no son el amor de su vida ${ }^{42}$.

\subsubsection{Autoría y recepción de las películas}

El papel del autor es fundamental dentro de la producción de Pasolini y de cómo entiende éste la creación cinematográfica. En su papel de cineasta presupone al auteur como maestro encargado de todos los detalles de la creación,

41 HALL, E., op. cit., p. 157.

42 BROCKETT, Oscar Gross, «Euripides Medea: Mythic Context and the Sense of Futurity», The Tulane Drama Review, 3 (1958), pp. 23-33. 
Versiones y revisiones cinematográficas de un mito clásico: las Medeas de Pasolini...

para así establecer una coherencia con el resto de su obra: «Si me decidí a hacer películas, es porque he querido hacerlas exactamente como escribo poesías, como escribo novelas. Yo debía ser forzosamente autor de mis películas, no podía ser un coautor ${ }^{43}$. La acogida fue bastante negativa por la mayor parte de los sectores. Si aún hoy resulta «difícil» de ver, no puede negársele el sentido intelectual que emana y, por tanto, no tendría porqué esperarse una fácil lectura. La cuestión es si el problema reside en que se presentó una obra demasiado difícil para un público mayoritariamente indocto en los temas que Pasolini plantea. Que un público de esas características no amparase la película tiene cierta lógica, sin embargo, tampoco los grupos intelectuales quisieron entenderla. Pasolini respondía diciendo: «pido a mis espectadores al menos el mismo trabajo que yo he puesto en la obra» ${ }^{44}$.

En el caso de Dassin tampoco puede hablarse de una muy buena acogida, al menos en el país donde fue rodado, no obstante, en Francia tuvo una muy justa recepción, aunque se infravaloró en cierta medida su sentido, rebajándola a una simple denuncia a la situación de la mujer, a modo de panfletario feminista. Aunque sí se trate este tema, hay otros que priman y son más sustanciales que éste para entender su mensaje. Pero fue su estreno en Estados Unidos donde llevó a tildarla de producto comercial que, en un acto de soberbia, quiso imitar al maestro Bergman en Persona. Sin embargo, su detenida observación con los años ha permitido que fuera mejor valorada, sobre todo si se tiene en cuenta que las mejores críticas vienen precisamente de filólogos expertos en la tragedia clásica ${ }^{45}$.

\subsubsection{La apoteosis de Medea. Intenciones últimas}

Para entender las pretensiones que movieron a Pasolini a recrear este pasado religioso incierto, qué mejor que citar alguno de los textos que escribía por esta época, donde se refiere a la importancia del pasado: «Ahora prefiero moverme en el pasado precisamente porque considero que la única fuerza contestataria del presente es el pasado: es una forma aberrante, pero todos los valores en los cuales nos hemos formado, con todas sus atrocidades, sus lados negativos, son los que pueden poner en crisis el presente ${ }^{46}$. Podríamos entender la confrontación entre mundo irreconciliables como otro ejemplo de esas «distopías» tan en boga en el siglo XX, traídas de la mano de Orwell, Huxley o Bradbury, donde las historias sólo conducen a un futuro terrible originado por los errores, normalmente, de un presente que niega el pasado y la cultura anterior. Podríamos acogernos a este sentido y cerrar el significado, pero bajo mi punto de vista y en acuerdo con Fernando González García, sería intentar proveer a la obra de Pasolini de un sentido pedagógico que creo nunca pretendió imprimirle, sino que, en ese esfuerzo que

43 GONZÁLEZ, F., op. cit., p. 28.

44 VICE, «ll Braccio di ferro di Pasolini», Avanti, 1970

45 VALVERDE GARCÍA, A., op. cit., p. 115.

46 FABROSCHI, A. A., op. cit., p. 181. 
ruega a sus espectadores, probablemente esté inscrito un significado abierto que sólo cada persona individualmente puede reconstruir en su interior, ya que como el propio Pasolini sostenía: «la única forma de pedagogía para personas libres viene de la poesía» 47 .

Para la película de Jules Dassin se atiende a la propuesta de Alejandro Valverde García, cuando apunta que en Gritos de Pasión se propone hacer una «reflexión en voz alta sobre el acto de la creación artística uniendo los campos del cine, la televisión y el teatro [...] añade una cuestión tan tristemente candente como la de la ética profesional en lo referente a los medios de comunicación, todo ello, con el trasfondo, ya de por sí complejo, de la tragedia de Medea que para él es poliédrica y la descompone en una Medea mítica, otra real (Brenda Collins) y otra imaginaria (Maya)»48. La película viene a mostrar algo que los griegos ya conocían bien: «[...] that the fate is nothing else but the passion and despair which inhabit a person»49. Al final somos conscientes de cómo Maya, no sólo intentó interiorizar su personaje sino a sí misma, auténtica Medea, asesina del hijo que llevaba en su vientre. Esto es lo que lan Christie presenta como la «oposición de la catarsis», ya que será capaz de adentrarse más profundamente en el papel de la ficción al reconocer que ya lo ha experimentado en su vida real ${ }^{50}$. El clímax de la película coincide con la identificación de las tres Medeas, que se ven fundidas en una sola, del mismo modo que en la película de Bergman, Persona (1966), Elisabeth Vogler (Liv Ullman) y Alma (Bibi Andersson) se acaban reconciliando en una misma persona, convertidas en «almas gemelas», cuya escena apoteósica es mostrada precisamente en la película de Dassin como homenaje, y clave para entender el proceso que se da en los dos personajes femeninos.

Lo que en la película de Trier se plantea es un análisis de lo que el público ateniense pudo sentir a la hora de ver la representación de la tragedia, pero ahora como público moderno e inmerso en la era de la tecnología ${ }^{51}$. La historia parece ser contada en flashback: Medea aparece tendida en el mar, inmersa en un éxtasis producido por los hechos acaecidos; acto seguido Egeo le garantiza ${ }^{52}$ asilo en la ciudad. Sus atroces planes pueden ser ejecutados. Lo que se nos muestra inmediatamente después es el cartel del filme: el nombre de la película con dos figuras ahorcadas. La solución que toma Medea está muy en consonancia con la que ocupará a las protagonistas de las próximas obras de Trier (la liberación a través de actos impropios): «Medea attempts to solve the moral dilemmas of the

47 Extraido de Il padre selvaggio de Pasolini, comentario de GONZÁLEZ GARCÍA, F., op. cit., p. 475. Estas ideas quedan expuestas en: PASOLINI, Pier Paolo, «Le Cinéma de poésie», Cahiers de Cinéma, 171 (1965), p. 55-65.

48 VALVERDE GARCÍA, Alejandro, «Gritos de Pasión: Tres Medeas para Jules Dassin», Estudios Neogriegos: Revista Científica de la Sociedad Hispánica de Estudios Neogriegos, 11 (2008), p.119.

49 MACKINNON, K, op. cit., p. 160.

50 HALL, E., op. cit., p. 161.

51 JOSEPH, S. y JOHNSON, M., op. cit., p. 113. Este artículo se presenta teniendo en cuenta la obra de Walter Benjamin: La Obra de Arte en la Era de su Reproductibilidad Técnica y parte de la psicología freudiana.

${ }_{52}$ Se trata de una garantía, no ya una promesa, como ocurría en Eurípides, por lo que aquí Medea se muestra completamente decidida ya, desde el inicio, a ejecutar su venganza. 
Versiones y revisiones cinematográficas de un mito clásico: las Medeas de Pasolini...

human condition, in her case an unfaithful partner, through an anarchic act of personally defined purity to achieve catharsis through suffering»53.

La principal razón por la que Ripstein y Garciadiego declaran seguir la versión del autor latino es porque, de alguna manera, invocan ese «laberinto de soledades» que le interesaba representar a Séneca. Una soledad que en la visión de Tovar Paz se manifiesta de forma múltiple: primero un abandono por parte de los dioses, lo que le permite llevar a cabo su decisión final sin hacer caso de los consejos de su nodriza, del mismo modo que Julia se lamenta: «Yo, la triste pendeja de mí, me vine para acá. Dejé todo, tuve hijos, los tuve por ti y para ti... Decías que querías sangre de mi sangre ¿no?»54. A ella también le ha abandonado Nicolás tras los que parecían sinceros juramentos, por lo que tiene «rienda suelta» para llevar a cabo su venganza. En segundo lugar plantea un abandono ritual, en el que se establece un paralelismo entre el rito del matrimonio y el de las muertes, así el abandono del primero se ve compensado con la sangre ritual que se derrama del segundo. En la película se plantea con los conceptos de aborto y virginidad. Julia es una «abortera» en contraste con la «virginal» Raquel, quien ha sustituido a la primera y, siendo virgen, puede realizar el rito del matrimonio. Así mismo, el hombre se alza con potestad absoluta para abandonar a la mujer, como un hecho evidente del que sólo queda la resignación y un cierto odio. La tercera soledad que se plantea es una legal, ya que Medea tiene derecho a reclamar su estancia, del mismo modo que Creonte-La Marrana de pedirle que se vaya por suponer una amenaza para su hija. Por último, se sugiere un abandono amoroso que en Séneca se justifica con que Jasón está intentando procurarse un futuro mejor para los hijos de ambos y que, en la película, se traslada a la plasmación de dos actos sexuales en una misma escena, uno real (Raquel-Nicolás) y otro que aparece en la televisión (Julia-Nicolás) ${ }^{55}$. La guionista alude al amor como invento moderno, sobre todo en el concepto de duración eterna, por ello aclara que en esta película lo que Julia repudia es que «él rompa el pacto y la deje de querer, y la tensión de él [...] es el triste pero sacrosanto derecho a dejar de querer a alguien».

\section{CONCLUSIONES}

Las cuatro propuestas analizadas plantean una visión muy particular del mito «revisitado», todas ellas conducen hacia una apoteosis final, la Medea ex machina que huyó en el carro alado de su abuelo Helios en un acto triunfal de liberación. De esta manera se han escogido cuatro frases de cada filme representativas de este momento, estableciendo un paralelismo con las últimas frases pronunciadas por las Medeas de la Antigüedad, que en Eurípides concluía diciendo, en boca de Corifeo: "Zeus en el Olimpo es el dispensador de muchos acontecimientos y muchas cosas, inesperadamente concluyen los dioses. Lo esperado no se llevó a cabo y de lo

\footnotetext{
53 JOSEPH, S. y JOHNSON, M., op. cit., p. 131.

54 GARCIADIEGO, P. A., op. cit., Madrid, Conaculta, 2001, p. 15.

55 Consideraciones tomadas de TOVAR PAZ, F. J., op. cit., p. 186-188.
} 
inesperado un dios halló el camino. Así se ha resuelto esta tragedia»56. En Séneca se concluye con una Medea cruel, ya que, aunque Jasón le implora la muerte, ésta no se la concede: J. «¡Cruel, dame la muerte!»; M. «¡Bien! ... ¡Todo está cumplido! ... ¡Furor, nada me queda que poder consagrarte!... Alza Jasón ingrato,/ tus ojos insolentes. ¿Conoces a tu esposa?/ Así suelo fugarme. Me abre camino el cielo./ Dos serpientes someten sus cuellos escamosos/ al yugo... Ahora, padre, recibe ya a tus hijos. / Yo surcaré los aires en este carro alado» 57.

Lo que los cineastas guardan para este final apoteósico es, en Pasolini una respuesta incierta de Medea a la pregunta de Jasón «¿Por qué lo has hecho?», a lo que ella alega: «Ya nada es posible», negándole cualquier tipo de explicación y dejándole así sumido en el mayor dolor, porque no ha justificado el daño causado. La Medea real de Juales Dassin da muestra de la venganza más mezquina al dejar una carta junto a los cadáveres de sus tres hijos con una dedicatoria que titula irónicamente: «To a wonderful father on a Father s Day». Lars von Trier recuerda la situación desamparada de los seres humanos descaminados, expuestos a dejarse llevar por las más espeluznantes decisiones: «Human life is a journey in the dark where only a God can find the way. That which nobody dares believe, God can make happen». Por último, Ripstein y Garciadiego, hacen gala de esa liberación que consigue Medea a través de la venganza, convirtiendo en inmortales a sus hijos y a ella misma: "Te me volví inolvidable».

En cualquier caso, intentar buscar paralelismos forzados entre las cuatro obras constituiría una vana labor, ya que cada una se presenta con unas características tan específicas, un espíritu tan definido en la personalidad de cada autor y unos sentidos tan variados que no podrían enumerarse para cerrarlos en un mensaje global, ya que cada espectador reflexiona en su interior los sentidos que a él le sugieren. En cualquier caso, la elección de estas Medeas se debe principalmente a la singularidad que plantean tanto en su revisión del mito como a la hora de presentarlo estética y argumentalmente, dentro de un medio perteneciente a la contemporaneidad pero desplegando una poética argumental y visual que sobrecoge al espectador actual del mismo modo que las tragedias clásicas lo hicieron con su público en la Antigüedad.

Al igual que no existen dos Medeas iguales, tampoco existe una lectura única para entender todas y cada una de las versiones que se han hecho de este mito desde que fuera llevado a escena por Eurípides hace más de veinte siglos, por lo que cada obra que tome esta como base, al final constituirá una labor novedosa y sin parangón: «[...] cada vez que esta tragedia se lleva a escena se convierte inmediatamente en un acto de reinterpretación del original en el que influye el espectador, la escenografía diseñada, la actuación de la protagonista, el momento concreto y también el lugar, por lo que no habrá nunca dos Medeas iguales [...] demuestra la riqueza del texto dramático y su inmortalidad»58.

56 EURÍPIDES, op. cit., p. 263. EUR. Med., 1415-1419.

57 SENECA, Lucio Anneo, op. cit., p. 122. SEN. Med., 1017-1025.

58 VALVERDE GARCÍA, A., op. cit., p. 118. 